\title{
Comparison of Enamel Fluoride Uptake from Five Fluoride-Containing Topical Treatment Products
}

\author{
Timothy Sedlacek, Erick Yu, Rolando Nunez, Byoung In Suh* \\ An employee of Bisco Inc, Schaumburg, Illinois, USA
}

*Corresponding author: Byoung In Suh, An employee of Bisco Inc, Schaumburg, Illinois, USA.

Received Date: October 15, 2020

Published Date: October 29, 2020

\begin{abstract}
Purpose: To observe and compare enamel fluoride uptake in enamel by three fluoride varnishes, a fluoride foam, and a fluoride gel.

Methods: Bovine incisors were ground and cut into six groups $(n=10)$ of cubic samples, set in resin cement such that a single square surface of facial enamel was exposed in each sample. These enamel surfaces were polished and treated, with a group assigned to each of three $5 \%$ sodium fluoride varnishes (BISCO, 3M ESPE, GC America), a fluoride foam (Dentsply Sirona), a fluoride gel (Crosstex International, Inc), as well as a water control group. After application of product, the samples were agitated at $37^{\circ} \mathrm{C}$ before removal of product by potassium hydroxide solution $(10 \mathrm{~mL}$, $1.0 \mathrm{M}$, saturated with calcium phosphate). A layer of exposed enamel was dissolved in each sample with perchloric acid $(2.5 \mathrm{~mL}, 1.0 \mathrm{M})$ which was then neutralized with sodium hydroxide. The resulting solution was buffered in TISAB II and measured for fluoride content by ion selective electrode (ISE), which was adjusted for sample surface area.

Results: Enamel Fluoride Uptake (EFU) was observed from each group with the following mean values and standard error: $8.32 \pm 0.44 \mu \mathrm{g} / \mathrm{cm}^{2}$, $6.11 \pm 0.62 \mu \mathrm{g} / \mathrm{cm}^{2}$, and $4.04 \pm 0.20 \mu \mathrm{g} / \mathrm{cm}^{2}$ in the BISCO, 3M ESPE, and GC America varnishes, $6.52 \pm 0.64 \mu \mathrm{g} / \mathrm{cm}^{2}$ in the fluoride foam, $7.03 \pm 0.51 \mu \mathrm{g} /$ $\mathrm{cm}^{2}$ in the fluoride gel, and $1.59 \pm 0.11 \mu \mathrm{g} / \mathrm{cm}^{2}$ in the control group.

\section{Clinical Significance}

When in contact with tooth enamel, topical fluoride treatments including varnishes, gels and foams can induce fluorapatite by chemically incorporating fluoride in the tooth structure. This enamel fluoride uptake can be measured and compared to guide clinicians on the relative efficacy of different fluoride treatments. Results demonstrated here show that the BISCO varnish has a statistically higher EFU compared to other tested products.
\end{abstract}

\section{Introduction}

Topical fluoride treatments have been established to reduce caries in children by as much as 25 percent [1]. Alongside fluoridated water supplies and fluoride-containing toothpaste, products specifically designed for fluoride delivery including varnishes, gels, and foams have become widespread. By introducing fluoride into outer layers of enamel (that is, 6-8\% replacement of $\mathrm{OH}^{-}$by $\mathrm{F}^{-}$in hydroxyapatite) [2], the fluoridated apatite (fluorapatite) has been shown to be more resistant to acid attack than untreated enamel and inhibit bacterial enzymes [3]. Furthermore, $5 \% \mathrm{NaF}$ varnishes have

been demonstrated to improve surface micro-hardness of enamel by incorporating fluoride and phosphate into the mineral structure [4]. Fluoride varnishes have been found to be as cariostatically efficacious as other preventive agents across numerous laboratory and clinical studies [5].

Aside from $5 \% \mathrm{NaF}$ varnishes, a leading source of fluoride for topical demineralization is acidulated phosphate fluoride (APF) [6]. APF is a NaF solution that has been buffered with phosphate and acidulated to $\mathrm{pH} 3-4$. This solution is incorporated, typically 
at $1.23 \%$, into various gels, foams, rinses, and other treatment products meant for short-term application. Unlike varnishes, which remain bound to tooth surface on the order of hours, APF products are designed to be applied and rinsed within minutes, prioritizing easy dispensation and clean-up over duration of contact. Although each varnish used in the present study contains exactly $5 \% \mathrm{NaF}$, the formulations are not otherwise identical. Different compositions of solvent, adhesive rosin, and emulsifiers impact the duration of contact and surface durability. In addition, two varnishes studied contain tri-calcium phosphate (TCP) ${ }^{\mathrm{a}, \mathrm{b}}$ while one contains amorphous calcium phosphate (ACP) ${ }^{c}$, all of which interact with the oral environment and can impact the chemical processes involved.

For many years, enamel fluoride uptake (EFU) has been a subject of particular study [7-9]. While in vitro models impose limitations on studying some complex biological processes such as those involved in caries, they are more regularly utilized in cases of chemical processes such as demineralization and fluoride uptake [10]. Bovine enamel has been considered an acceptable alternative to human dentin for in vitro study of EFU $[10,11]$. When fluoride ions in solution come into contact with an enamel surface, formation of fluorapatite will occur that can be detected even after thorough rinsing of the enamel surface [2]. Loosely bound deposits of $\mathrm{CaF}_{2}$ or varnish bulk material can be readily dissolved to leave only the enamel surface and any structurally bound fluoride. The enamel specimens in the present study were treated with a procedure similar to method \#40 described in the FDA monograph and those of other studies based on the same method [12,13].

\section{Materials and Methods}

Whole bovine incisors were ground with wet trimmer to remove roots, tapered ends of crowns, and otherwise reduce each incisor to rectangular shape. Each incisor was sectioned along pulp chamber parallel to facial surface to produce rectangular blocks of facial enamel. Each enamel block was sectioned in a grid pattern at intervals of $2.5 \mathrm{~mm}$ to produce samples of approximately $2.5 \mathrm{~mm}$ x $2.5 \mathrm{~mm} \times 5 \mathrm{~mm}$ with a rectangular facial enamel surface exposed. Enamel samples were placed in stainless steel split molds $(3 \mathrm{~mm}$ height, $6 \mathrm{~mm}$ diameter) which were in turn positioned on square Mylar sheets on square glass plates. The molds were filled with non-fluoride-containing resin luting cement (Duo-Link $\left.{ }^{a}\right)$ such that only the facial enamel surface of each sample was exposed. Samples were polished with wet 600 grit sandpaper to achieve even surface of enamel and cement. Each sample was dried and weighed at room temperature, and the dimensions of exposed facial enamel were recorded.
Six groups of ten samples were prepared. Three group assigned to $5 \%$ sodium fluoride varnishes (corresponding to $22,600 \mathrm{ppm}$ F-ion): BISCO Varnish ${ }^{\mathrm{a}}$, Vanish ${ }^{\mathrm{b}}$, and MI Varnish ${ }^{\mathrm{c}}$. In addition, groups were assigned to Nupro Fluoride Foam ${ }^{\mathrm{d}}$ and Zap Fluoride Gel ${ }^{\mathrm{e}}$ containing $1.23 \%$ acidulated phosphate fluoride (corresponding to $12,300 \mathrm{ppm}$ F-ion). The final group was assigned to water control. Products were applied in thin layers to respective samples with bristle brush applicators. Each sample was weighed after product application to determine mass of product applied. Samples of varnish were immersed in individual vials of deionized water $(10 \mathrm{~mL})$ and agitated with an orbital shaker for 24 hours at $37^{\circ} \mathrm{C}$. Gel and foam samples were likewise immersed in individual vials but were agitated for 30 minutes according to product use instructions.

In order to remove material from the treatment products as well as loosely bound fluoride, each sample was immersed for 18 hours in potassium hydroxide solution $(10 \mathrm{~mL}, 1.0 \mathrm{M}$, saturated with calcium phosphate). After treatment, samples were rinsed with deionized water and air-dried, then blotted and wiped to remove any remaining fluoride product and/or precipitated calcium phosphate. In order to dissolve a layer of cleaned enamel, samples were individually immersed in $2.5 \mathrm{~mL}$ perchloric acid $(1.0 \mathrm{M})$ for 15 seconds each. After removal of sample, this solution was neutralized with $2.5 \mathrm{~mL}$ of sodium hydroxide $(1.0 \mathrm{M}) .5 .0 \mathrm{~mL}$ of TISAB II solution was added with magnetic stir bar to each solution to create test specimens. The fluoride content of each test specimen was determined with fluoride Orion $720 \mathrm{~A}$ ISE standardized by 4-point fluoride concentration curve $\left(1 \times 10^{-4} \mathrm{M}, 1 \times 10^{-3} \mathrm{M}, 1 \times 10^{-2}\right.$ M, $1 \times 10^{-1} \mathrm{M}$ sodium fluoride buffered with TISAB II). The fluoride contents of dissolved enamel for each set of samples were adjusted for exposed enamel surface area and mass of product applied. Each set of fluoride uptake results were analyzed against each other's result set by Student's t-test for statistical significance $(p<0.05)$.

\section{Results}

Enamel fluoride uptake was determined by normalizing final solution fluoride concentrations to the calculated surface areas of each corresponding sample (Table 1). The observed EFU was highest for the BISCO varnish, followed by the gel, the foam, the $3 \mathrm{M}$ varnish, and the GC varnish. Statistical comparisons were performed between each test group (Table 2). The calculated EFU for the BISCO varnish was statistically significantly higher ( $p$ $<0.05$ ) than that of the Fluoride foam, the 3M and GC varnishes, and the control. All treated test groups had significantly higher EFU than the control group $(\mathrm{p}<0.0001)$.

Table 1: Enamel Fluoride Uptake by Test Group $(n=10)$, Letters denote groups with statistically significant difference $(p<0.05)$.

\begin{tabular}{|c|c|c|c|c|c|c|}
\hline & BISCO Varnish $(\boldsymbol{\alpha})$ & Fluoride Gel $(\boldsymbol{\beta})$ & Fluoride Foam $(\gamma)$ & 3M Varnish $(\delta)$ & GC Varnish $(\varepsilon)$ & Control $(\zeta)$ \\
\hline EFU $\left(\mu \mathrm{g} \mathrm{F}-/ \mathrm{cm}^{2}\right)$ & $8.32 \gamma \delta \varepsilon \zeta$ & $7.03 \delta \varepsilon \zeta$ & $6.52 \alpha \varepsilon \zeta$ & $6.11 \alpha \zeta$ & $4.04 \alpha \beta \gamma \zeta$ & $1.59 \alpha \beta \gamma \delta \varepsilon$ \\
\hline Standard Deviation & 1.4 & 1.62 & 2.04 & 1.96 & 0.63 & 0.35 \\
\hline Standard Error & 0.44 & 0.51 & 0.64 & 0.62 & 0.2 & 0.11 \\
\hline Variance & 1.97 & 2.63 & 4.16 & 3.86 & 0.39 & 0.12 \\
\hline
\end{tabular}


Table 2: Comparison of t-test (P-values) on EFU Data between each test set.

\begin{tabular}{|c|c|c|c|c|c|c|}
\hline & BISCO Varnish & Fluoride Gel & Fluoride Foam & 3M Varnish & GC Varnish & Water Control \\
\hline BISCO Varnish & $\mathrm{X}$ & 0.0729 & 0.0335 & 0.0096 & $<0.0001$ & $<0.0001$ \\
\hline Fluoride Gel & 0.0729 & $\mathrm{X}$ & 0.5438 & 0.2685 & $<0.0001$ & $<0.0001$ \\
\hline Fluoride Foam & 0.0335 & 0.5438 & $\mathrm{X}$ & 0.6525 & 0.0017 & $<0.0001$ \\
\hline 3M Varnish & 0.0096 & 0.2685 & 0.6525 & $\mathrm{X}$ & 0.0053 & $<0.0001$ \\
\hline GC Varnish & $<0.0001$ & $<0.0001$ & 0.0017 & 0.0053 & $\mathrm{X}$ & $<0.0001$ \\
\hline Water Control & $<0.0001$ & $<0.0001$ & $<0.0001$ & $<0.0001$ & $<0.0001$ & $<0.0001$ \\
\hline
\end{tabular}

\section{Discussion}

In this study, the fluoride treatment products fall into two broad categories, with the three varnishes ${ }^{\mathrm{a}, \mathrm{b}, \mathrm{c}}$ containing $5 \%$ sodium fluoride (NaF) and the foamd and gele containing 1.23\% APF. The observed fluoride uptake of Nupro Fluoride Foam was the third highest, but in some instances, it has been observed that $5 \% \mathrm{NaF}$ based varnishes outperformed APF-based treatments [9]. This was correlated to the conclusion that lower fluoride-containing varnishes promoted fluorapatite formulation, which was more resistant to dissolution where as APF-containing varnishes rapidly formed $\mathrm{CaF}_{2}$ which would readily wash out when exposed to the oral environment.

In a similar study comparing the efficacy of APF-based products and other NaF-based varnishes, Bryant et al. [7] also observed that both the polyurethane-and rosin-based varnishes had a greater fluoride uptake than the APF-based product. This however was not statistically different when comparing tensile bond strengths of treated enamel surfaces, indicating that the microstructure changes due to fluoride introduction did not increase bond strength to the control, APF, or NaF treated surfaces. While not investigated here, the chemical composition of varnishes and their impact in forming a resistant and insoluble coating would likely affect the fluoride uptake. Fluor Protectorf, which contains fluorosilane in a polyurethane base, likely introduces a more hydrophobic and resistant surface that could improve retention of the varnish.

When reviewing earlier studies however, there is contradicting evidence that APF-based treatments resulted in greater fluorideuptake [1] likely impacted by the methodology used when performing the treatments and analyses. This is supported by Arends and Schuthof [8] which observed the greatest fluoride concentration in APF-treated enamel immediately after treatment, but after normalized rinsing procedure (3 minutes for APF and 24 hours for Fluor Protector), the urethane dental varnish containing $\mathrm{NaF}$ left considerably greater fluoride content in the enamel. It was suggested both time of exposure and solubility of fluoride ions in APF played a role which allowed Fluor Protector ${ }^{\mathrm{f}}$ to form fluorapatite whereas APF solutions readily wash out.

In more recent years, fluoride varnishes began to include both ACP and TCP as calcium and phosphate-containing sources. These are for example, MI Varnish ${ }^{\mathrm{c}}$ and Vanish ${ }^{\mathrm{b}}$ respectively. In one study
[12] it was observed that the ACP-based treatment resulted in a much greater fluoride uptake over the TCP counterpart. It was suggested that the crystalline structure of TCP (similar to apatitic calcium phosphate found in enamel) prevents its solubility and incorporation into enamel whereas ACP, being amorphous, was more soluble and more reactive.

These results are consistent with another study by Shen, etal. [14] where MI Varnishc, containing CPP-ACP (casein phosphopeptideamorphous calcium phosphate), also demonstrated the greatest calcium and fluoride release. However as also postulated, the authors commented that the substantial release did not indicate a correlation to actual uptake and permanence when incorporated into enamel. This was due to the lack of structural analysis comparing if fluoride was precipitated or incorporated as fluorapatite in the enamel. In the study presented here, MI Varnish ${ }^{c}$ had the lowest fluoride-uptake of all varnishes tested, suggesting that despite (or perhaps because of) high fluoride and calcium release, the CPP-ACP is relatively soluble and possibly lost from extraction and rinsing after application. For a controlled concentration of fluoride in formulation (2.26\% by molecular mass in the varnishes), higher ion release in solution naturally corresponds to lower concentration remaining in the material contacting the enamel surface.

Mellberg, Bolis C $[15,16]$ noted that from various topical fluoride treatments studied in the 1970s and 1980s that the formulation and composition played an important role from imprecision of clinical trials and observations to studies on early products containing $\mathrm{APF}, \mathrm{NaF}$, and stannous fluoride. Even to current formulations and ranges of products, this comment still is accurate and seen from studies performed in recent years.

Fluoride release rate does not by itself predict enamel fluoride uptake, as argued in a newer study [16] which compares several varnishes for their alkali-soluble fluoride and structurally bound fluoride content. Fluor Protector $S^{f}$ continued to have the highest concentration of structurally bound fluoride (considered as fluoride uptake for the study presented here), despite having the lowest ppm content of available fluoride. MI Varnish ${ }^{c}$ also was observed to have the greatest release of fluoride, confirming other studies which suggested ACP-type compounds were more soluble [14].

Simply increasing the concentration of fluoride can introduce unwanted side-effects such as fluorosis without superior 
cariostatic outcomes [17]. It has been argued that sustained, moderate concentrations of fluoride in oral fluids provides the best balance of caries prevention and enamel maintenance [2]. Therefore, simple measurement of fluoride release into solution is insufficient to predict fluorapatite formation. In conclusion, enamel fluoride uptake cannot be predicted solely by ion release rates, or by fluoride source in formulation. Higher release rates of fluoride ion into solution could lead to more precipitation of $\mathrm{CaF}_{2}$ without formation of structurally bound fluoride. Solubility, retention time, and chemical composition are also significant factors in uptake, leading to the observed result that one $5 \% \mathrm{NaF}$ varnish (BISCO Varnish $^{\text {a) }}$ had higher enamel fluoride uptake than the APF gel (Zap Fluoride Gele) and foam (NuPro Fluoride Foam ${ }^{\mathrm{d}}$ ), which in turn had higher EFU than the other two 5\% NaF varnishes (Vanish ${ }^{\mathrm{b}}$ and MI Varnish ${ }^{\mathrm{c}}$.

\section{Manufacturer Information}
a. BISCO, Schaumburg, IL, USA
b. 3M ESPE, St. Paul, MN, USA
c. GC America, Alsip, IL, USA
d. Dentsply Sirona, York, PA, USA
e. Crosstex International, Inc, Hauppauge, NY, USA
f. Ivoclar Vivadent Inc, Amherst, NY, USA

\section{Acknowledgement}

None.

\section{Conflict of Interest}

The authors declare no conflict of interest.

\section{References}

1. Aasenden R, DePaola PF, Brudevold F (1972) Effects of Daily Rinsing and Ingestion of Fluoride Solutions upon Dental Caries and Enamel Fluoride. Arch Oral Biol 17 (12): 1705-1714.

2. Buzalaf MAR, Pessan JP, Honório HM, ten Cate JM (2011) Mechanisms of Action of Fluoride for Caries Control. Monogr Oral Sci 22: 97-114.

3. Featherstone JDB (1999) Prevention and Reversal of Dental Caries: Role of Low-Level Fluoride. Community Dent Oral Epidemiol 27(1): 31-40.
4. AlAmoudi SA, Pani SC, AlOmari M (2013) The Effect of the Addition of Tricalcium Phosphate to 5\% Sodium Fluoride Varnishes on the Microhardness of Enamel of Primary Teeth. Int J Dent 486358.

5. Beltrán Aguilar ED, Goldstein JW, Lockwood SA (2000) Fluoride Varnishes: A Review of Their Clinical Use, Cariostatic Mechanism, Efficacy and Safety. J Am Dent Assoc 131(5): 589-596.

6. Taiema A, Taiema D (2017) Efficacy of Nanohydroxyapatite versus Acidulated Phosphate Fluoride on Initial Demineralized Enamel Surface (In Vitro Study). Egypt Dent J 63: 781:790.

7. Bryant S, Retief DH, Bradley EL, Denys FR (1985) The Effect of Topical Fluoride Treatment on Enamel Fluoride Uptake and the Tensile Bond Strength of an Orthodontic Bonding Resin. Am J Orthod 87(4): 294-302.

8. Arends J, Schüthof J (1975) Fluoride Content in Human Enamel after Fluoride Application and Washing- An in Vitro Study. Caries Res 9(5): 363-372.

9. Retief DH, Bradley EL, Holbrook M, Switzer P (1983) Enamel Fluoride Uptake, Distribution and Retention from Topical Fluoride Agents. Caries Res 17(1): 44-51.

10. White DJ (1995) The Application of In Vitro Models to Research on Demineralization and Remineralization of the Teeth. Adv Dent Res 9(3): 175-193.

11. Schemehorn BR, Famham RL, Wood GD, Stookey GK (1992) Fluoride Uptake and Remineralization in Human and Bovine Enamel. J Dent Res 71: 186.

12. Schemehorn B, Wood G, Mchale W, Winston A (2011) Comparison of Fluoride Uptake into Tooth Enamel from Two Fluoride Varnishes Containing Different Calcium Phosphate Sources. J Clin Dent 22: 51-54.

13. Schemehorn BR, DiMarino JC, Movahed N (2014) Comparison of the Incipient Lesion Enamel Fluoride Uptake from Various Prescription and OTC Fluoride Toothpastes and Gels. J Clin Dent 25: 57-60.

14. Shen P, Bagheri R, Walker G, Yuan Y, Stanton D, Reynolds C, Reynolds E (2016) Effect of Calcium Phosphate Addition to Fluoride Containing Dental Varnishes on Enamel Demineralization. Aust Dent J 61(3): 357365 .

15. Bolis C, Härtli G, Lendenmann U (2015) Fluoride Varnishes-Is There a Correlation Between Fluoride Release and Deposition on Enamel? Oral Health Prev Dent 13(6): 545-56

16. Mellberg JR (1990) Evaluation of Topical Fluoride Preparations. J Dent Res 771-779.

17. Carey CM (2014) Focus on Fluorides: Update on the Use of Fluoride for the Prevention of Dental Caries. J Evid Based Dent Pract 14: 95-102. 